\title{
Evolution of cataract surgery in relation to visual outcome and ease of surgery in eye camps in Meerut and vicinity (Northern India)
}

\author{
Santosh Kumar ${ }^{1 *}$, Basant Kumar Singh ${ }^{2}$, Sushank Ashok Bhalerao ${ }^{3}$ \\ ${ }^{1}$ Associate Professor, ${ }^{2}$ Medical Officer, ${ }^{3}$ Senior Resident, ${ }^{1-3}$ Dept. of Ophthalmology, ${ }^{1-3}$ Regional Institute of Ophthalmology at govt. M. D. \\ Eye Hospital, Allahabad, Uttar Pradesh, India
}

\begin{abstract}
Objective: To study evolution of cataract surgery (from ECCE to manual small incision cataract surgery to phaco-emulsification) in relation to ease of surgery and visual outcome in eye camps in northern India.

Design: Cross-sectional study

Materials and Methods: The study included 780 patients who underwent cataract surgery following screening of 4763 patients at community screening camps. Patients underwent ECCE (Extra-capsular cataract extraction), SICS (small-incision cataract surgery) and phaco-emulsification with intraocular lens implantation under local anaesthesia at the base hospital. Patients were followed up on 1st day, 1st week, 6th week, 3rd month, and 6th month postoperatively. Postoperative complications and visual outcome were recorded.

Main Outcome Measures: Visual outcome and complications in patients undergoing surgery

Results: Among the 4763 patients seen in OPD, almost two-third of patients were between 41 to 70 years of age and approximately half $(52.82 \%)$ of patients were females. Cataract $(53.52 \%)$, refractive error $(16.75 \%)$ and corneal scarring $(8.34 \%)$ were among leading causes of ocular morbidity.Out off 780 patients selected for cataract surgery, most were between $40-60$ years of age $(82 \%)$ and $52.5 \%$ were females.82\% of patients were from lower socio-economic class. Complication rate was more in ECCE with PCIOL group and less in Phaco-emulsification with PCIOL group. Best corrected visual acuity at 6 weeks follow up was better in SICS and phaco-emulsification group while average numbers of follow up visits were less in these two groups as compared to other two groups.

Conclusion: Our study reflects the efficacy of the base hospital approach and also adopting newer surgical approaches at base camps gives easily visual rehabilitation, better visual outcomes and compliance, and lesser complications compared to older methods. Phacoemulsification and small incision cataract surgery are safer than conventional ECCE surgery.
\end{abstract}

Keywords: Base hospital, Extra-capsular cataract extraction, Phaco-emulsification, Small-incision cataract surgery.

\section{Introduction}

Globally, cataract is the leading cause of reversible blindness and visual impairment. ${ }^{1-3}$ Blindness from cataract is more frequent in populations with low socioeconomic status and in developing countries than in developed countries. $^{4,5}$ The only treatment for cataract is surgical removal and replacement of the lens with a permanent artificial intraocular lens (IOL). Successful cataract surgery universally improves vision as well as quality of life. Phacoemulsification is the gold standard for cataract surgery in the developed world. In contrast, small incision cataract surgery (SICS) with a self-sealing and sutureless incision is frequently used in low- and middle-income countries. Both phacoemulsification and SICS achieve good visual results; more than 13 million cataract surgeries were performed globally in 2013. . $^{1,2}$

Various risk factors can complicate cataract surgery, leading, for example, to a small pupil or to rupture of the posterior capsule during surgery. However, if properly managed, most complications are still compatible with good visual outcomes.

The greatest challenge remains the growing prevalence and 'backlog' of patients with cataract blindness in the developing world. In these countries, there is a lack of access to affordable surgery, and efforts aimed at training cataract surgeons do not keep pace with the changing population demographics and increasing rates of cataract. A cataract surgery rate of 400 operations per lac population is required to enable the sates to clear the backlog cataract blindness. As there are no methods available to prevent or delay cataract development, greater attention is needed to guarantee effective delivery of cataract surgery in underserved areas.

As mentioned in 2010 Global Burden of Disease Study ${ }^{2}$ and other worldwide meta-analyses, ${ }^{4,5} 32.4$ million individuals worldwide were blind (visual acuity $<3 / 60$; with $60 / 60$ representing normal vision) and 191 million individuals were visually impaired (visual acuity $<20 / 60$ but $\geq 3 / 60$ ) in 2010. Globally, the leading overall cause of blindness was cataract, followed by uncorrected refractive error; uncorrected refractive error was the leading global cause of moderate to severe visual impairment, followed by cataract.

In India, maby non-governmental agencies have established cost-effective programmes that provide safe, effective interventions for cataract for such patients. Most of these

*Corresponding Author: Santosh Kumar, Dept. of Ophthalmology, Regional Institute of Ophthalmology at govt. M. D. Eye Hospital, Allahabad, Uttar Pradesh, India

Email: drsantosh7373@gmail.com

http://doi.org/10.18231/j.ijooo.2019.031 
programmes include outreach and screening patients in villages; those with cataracts are then brought to the hospital for surgery, and postoperative care is provided at their village. Cost can be reduced by maximizing the use of available resources, including the use of reusable materials, which are generally less costly than disposables. Many of the centres providing such surgery also have 'paying sections' for patients who can afford it, and part of this income is used to subsidize the 'free service' section. However, these centres depend on skilled surgeons who are willing to work for a cost-effective salary.

In the abovementioned model, the patient does not have to pay at all, and the costs of the surgery are subsidized partly from government grants, partly from voluntary donations from affluent members of society and partly from the hospital itself. These efforts have improved access to cataract surgery, which has resulted in marked reduction in the burden of cataract blindness in India. ${ }^{6}$

We studied evolution of cataract surgery (from ECCE to manual small incision cataract surgery to phacoemulsification) in relation to ease of surgery and visual outcome in eye camps in northern India.

\section{Materials and Methods}

The present study was done by the team consisting of Ophthalmologist and junior resident from LLRM medical College, Meerut, India by conducting screening Camps in various rural areas of district Meerut. The Institutional Review Board/Ethics Committee of LLRM medical College, Meerut, India where this study was conducted, approved the study protocol, and all patients provided written informed consent to participate. In these camps patients were treated, prescribed spectacles and those who were selected for cataract surgery were mobilized to medical college hospital. In the hospital these patients underwent cataract surgery by different surgical methods. Various factors affecting the overall visual result, costeffectiveness and patient compliance of follow up using different techniques and approaches of cataract surgeries(ECCE,SICS, Phacoemulsification) were analyzed.

For ECCE and SICS, patients with all types of senile cataract were included and for phacoemulsification, patients having immature cataract (Grade 1, 2 and 3) were included. One eyed patients, patients with subluxated lens, corneal dystrophies, corneal opacities, shallow anterior chamber, pre-existing ocular surgery, uveitis and patients having both cataract and glaucoma were excluded from study.

Statistical analysis was done using percentage and graphical presentations.

Initial examination of the eyes was done with torch light and loupe, and the eye with poorer vision was considered for eye surgery. Preoperative visual acuity, slit lamp examination and fundus examination was done. IOP measurement was done using Schiotz tonometer, and sac syringing to test the patency of lacrimal passages was done in all cases. Keratometry readings were taken, A-scan for axial length and biometry was done to determine intraocular lens (IOL) power. Blood investigations such as total blood count, differential count, hemoglobin, and random blood sugar level were done in all cases. B-scan was done in all cases of mature cataracts where the fundus view could not be obtained.

Prophylactic topical antibiotic drops (ciprofloxacin eye drops) 4 hourly and a single dose oral antibiotic (tablet ciprofloxacin $500 \mathrm{mg}$ ) were given one night prior to surgery.

Postoperatively all patients received oral antibiotics. Topical antibiotic steroid eye drops for 6 weeks in tapering dose along with flurbiprofen eye drops 8 hourly for 3 weeks. Follow-up visits were scheduled for the 1st day, 1st week, 6th week, 3rd month, and 6th month postoperatively. At each visit, slit lamp examination, IOP measurement using Perkins tonometer, and fundus findings were recorded, in addition to visual acuity and refraction. Spectacle correction was given at the end of 6th week.

\section{Results}

The eye camps were organized with the help of District Blindness Control Society and non-governmental organisations (NGO's). These eye camps were held at Nai Basti $(10.7 \mathrm{~km})$, Sisoli $(7.5 \mathrm{~km})$, Incholi $(15.7 \mathrm{~km})$, Bhawanpur $(7.7 \mathrm{~km})$, Amhera $(9.2 \mathrm{~km})$, Kasthala $(8.6 \mathrm{~km})$, Aadh (22 km), Jai Bheem Nagar(1.4 km), Bhagwatpura (4.9 $\mathrm{km})$, Multan Nagar $(9.7 \mathrm{~km})$, Bhagwanpur $(12.4 \mathrm{~km})$, Kaseru Baksar (8.8 km), Rasulpur Aurangabad(11.9 km), Dr. Zakir colony $(2.9 \mathrm{~km})$, Mundali $(17.8 \mathrm{~km})$, Meerpur $(39.1 \mathrm{~km})$, PHC Kharkhauda $(16.5 \mathrm{~km})$, Sita Pur Jr.high school(10.1 $\mathrm{km})$, Shastri Nagar $(2.7 \mathrm{~km})$. In all these camps, total 4763 patients were examined in the outpatient clinic, of which 815 were selected for cataract surgery and transported to medical college for cataract surgery.

Table 1 shows total number of patients seen in each OPD and number of patients selected for cataract surgery from each place. Almost two-third of patients were between 41 to 70 years of age and approximately half $(52.82 \%)$ of patients were females (table 2). Cataract (53.52\%), refractive error (16.75\%) and corneal scarring $(8.34 \%)$ were among leading causes of ocular morbidity. Out off 780 patients selected for cataract surgery, most were between $40-60$ years of age $(82 \%)$ and $52.5 \%$ were females (table $3) .82 \%$ of patients were from lower socio-economic class (table 4). Complication rate was more in ECCE with PCIOL group and less in Phaco-emulsification with PCIOL group (table 5). Best corrected visual acuity at 6 weeks follow up was better in SICS and Phaco group (table 6) while average number of follow up visits were less in these two groups as compared to other two groups (Table 7). 
Table 1: Eye camps at a glance

\begin{tabular}{|l|c|c|}
\hline \multicolumn{1}{|c|}{ Place } & $\begin{array}{c}\text { Total Number of } \\
\text { Patients seen }\end{array}$ & $\begin{array}{c}\text { Number of patients selected for } \\
\text { cataract surgery }\end{array}$ \\
\hline Nai Basti $(10.7 \mathrm{~km})$ & 297 & 44 \\
\hline Sisoli $(7.5 \mathrm{~km})$ & 253 & 71 \\
\hline Incholi $(15.7 \mathrm{~km})$ & 210 & 42 \\
\hline Bhawanpur $(7.7 \mathrm{~km})$ & 267 & 72 \\
\hline Amhera $(9.2 \mathrm{~km})$ & 220 & 43 \\
\hline Kasthala $(8.6 \mathrm{~km})$ & 213 & 31 \\
\hline Aadh $(22 \mathrm{~km})$ & 227 & 67 \\
\hline Jai Bheem Nagar(1.4 km) & 207 & 26 \\
\hline Bhagwatpura $(4.9 \mathrm{~km})$ & 207 & 28 \\
\hline Multan Nagar $(9.7 \mathrm{~km})$ & 215 & 45 \\
\hline Bhagwanpur(12.4 km) & 172 & 49 \\
\hline Kaseru Baksar(8.8 km) & 188 & 0 \\
\hline Rasulpur Aurangabad(11.9 km) & 209 & 39 \\
\hline Dr. Zakir colony $(2.9 \mathrm{~km})$ & 474 & 54 \\
\hline Kaserukhera $(7.1 \mathrm{~km})$ & 90 & 11 \\
\hline Mundali $(17.8 \mathrm{~km})$ & 120 & 26 \\
\hline Meerpur $(39.1 \mathrm{~km})$ & 208 & 26 \\
\hline PHC Kharkhauda $(16.5 \mathrm{~km})$ & 486 & 109 \\
\hline Sita Pur Jr.high school $(10.1 \mathrm{~km})$ & 367 & 17 \\
\hline Shastri Nagar $(2.7 \mathrm{~km})$ & 133 & 15 \\
\hline \multicolumn{1}{|c|}{ Total } & 4763 & 815 \\
\hline
\end{tabular}

Table 2: Age and sex distribution of OPD patients

\begin{tabular}{|c|c|c|}
\hline Age Group (Years) & Number of Patients & Percentage \\
\hline$<10$ & 140 & $2.94 \%$ \\
\hline $11-20$ & 263 & $5.52 \%$ \\
\hline $21-30$ & 366 & $7.68 \%$ \\
\hline $31-40$ & 557 & $11.69 \%$ \\
\hline $41-50$ & 1285 & $26.98 \%$ \\
\hline $51-60$ & 1255 & $26.35 \%$ \\
\hline $71-70$ & 783 & $16.44 \%$ \\
\hline$>80$ & 95 & $1.99 \%$ \\
\hline Sex & 19 & $0.40 \%$ \\
\hline Male & & \\
\hline Female & 2247 & $47.18 \%$ \\
\hline Total & 2516 & $52.82 \%$ \\
\hline
\end{tabular}

Table 3: Age and sex distribution and methods of cataract surgery in operated patients

\begin{tabular}{|c|c|c|}
\hline Age Groups (years) & Number of Patients & Percentage \\
\hline $40-50$ & 285 & 36.54 \\
\hline $51-60$ & 355 & 45.52 \\
\hline $61-70$ & 80 & 10.26 \\
\hline$>70$ & 60 & 7.69 \\
\hline Sex & & 47.44 \\
\hline Male & 370 & 52.56 \\
\hline Female & 410 & \\
\hline Methods & & 2.56 \\
\hline ECCE & 20 & 53.97 \\
\hline ECCE with PC-IOL implant & 421 & 23.46 \\
\hline Small incision cataract surgery & 183 & 20.00 \\
\hline Phacoemulsification with PC-IOL implant & 156 & 100 \\
\hline Total & 780 & \\
\hline
\end{tabular}


Table 4: Distribution of operated patients according to socioeconomic status

\begin{tabular}{|l|c|c|c|}
\hline \multicolumn{1}{|c|}{ Class } & Nalwa Criteria Per capita land (Bigha) & No. of Patients & Percentage \\
\hline Upper class (I) & 34 or more & 20 & 2.56 \\
\hline Upper middle class(II) & $18-33$ & 35 & 4.49 \\
\hline Lower middle class(III) & $9-17$ & 110 & 14.10 \\
\hline Upper lower class(IV) & $4-8$ & 255 & 35.69 \\
\hline Lower class(V) & $<4$ & 360 & 46.15 \\
\hline \multicolumn{1}{|c|}{ Total } & & 780 & 100 \\
\hline
\end{tabular}

Table 5: Complications following different surgical methods

\begin{tabular}{|l|c|c|c|c|c|c|c|c|}
\hline \multirow{2}{*}{ Complications } & \multicolumn{2}{|c|}{ ECCE } & \multicolumn{2}{c|}{$\begin{array}{c}\text { ECCE with } \\
\text { PCIOL }\end{array}$} & \multicolumn{2}{c|}{$\begin{array}{c}\text { SICS with } \\
\text { PCIOL }\end{array}$} & \multicolumn{2}{c|}{$\begin{array}{c}\text { Phacoemulsification } \\
\text { with PCIOL }\end{array}$} \\
\cline { 2 - 10 } & $\begin{array}{c}\text { Number } \\
\text { of patients }\end{array}$ & Percentage & $\begin{array}{c}\text { Number } \\
\text { of patients }\end{array}$ & Percentage & $\begin{array}{c}\text { Number of } \\
\text { patients }\end{array}$ & Percentage & $\begin{array}{c}\text { Number } \\
\text { of patients }\end{array}$ & Percentage \\
\hline Hyphaema & 0 & 0 & 2 & 0.47 & 0 & 0 & 0 & 0 \\
\hline Corneal edema & 0 & 0 & 4 & 0.95 & 1 & 2.56 & 2 & 0.66 \\
\hline AC reaction & 0 & 0 & 6 & 1.90 & 1 & 2.56 & 0 & 0 \\
\hline Iris prolapse & 0 & 0 & 3 & 0.71 & 0 & 0 & 0 & 0 \\
\hline Pupillary capture & 0 & 0 & 6 & 1.42 & 0 & 0 & 0 & 0 \\
\hline Decentrated IOL & 0 & 0 & 4 & 0.95 & 0 & 0 & 0 & 0 \\
\hline $\begin{array}{l}\text { Posterior Capsular } \\
\text { rent }\end{array}$ & 0 & 0 & 8 & 2.85 & 1 & 2.56 & 2 & 0.66 \\
\hline $\begin{array}{l}\text { Cystoid macular } \\
\text { edema }\end{array}$ & 0 & 0 & 3 & 1.90 & 1 & 2.56 & 1 & 0.33 \\
\hline $\begin{array}{l}\text { Suture-related } \\
\text { complications }\end{array}$ & 1 & 5 & 12 & 2.85 & 0 & & 0 & \\
\hline \multicolumn{1}{|c|}{ Total } & 1 & 5 & 48 & & 4 & & 5 & \\
\hline
\end{tabular}

Table 6: Best corrected visual acuity at 6 weeks follow up with different methods of cataract surgery

\begin{tabular}{|c|c|c|c|c|}
\hline Visual acuity & ECCE & $\begin{array}{c}\text { ECCE with } \\
\text { PCIOL }\end{array}$ & $\begin{array}{c}\text { SICS with } \\
\text { PCIOL }\end{array}$ & $\begin{array}{c}\text { Phacoemulsification } \\
\text { with PCIOL }\end{array}$ \\
\cline { 2 - 5 } & $\begin{array}{c}\text { Number of } \\
\text { patients(\%) }\end{array}$ & $\begin{array}{c}\text { Number of } \\
\text { patients }(\%)\end{array}$ & $\begin{array}{c}\text { Number of } \\
\text { patients }(\%)\end{array}$ & Number of patients (\%) \\
\hline $20 / 20-20 / 30$ & $10(50)$ & $352(83.61)$ & $173(94.54)$ & $137(87.82)$ \\
\hline $20 / 40-20 / 60$ & $6(30)$ & $42(9.98)$ & $10(5.46)$ & $15(9.61)$ \\
\hline $20 / 80-20 / 120$ & $4(20)$ & $13(3.09)$ & 0 & $1(0.65)$ \\
\hline $20 / 200$ or less & 0 & $14(3.33)$ & 0 & $3(1.92)$ \\
\hline & & & & 183 \\
\hline Total & 20 & 421 & & 156 \\
\hline
\end{tabular}

Table 7: Average number of visits in different methods of cataract surgery

\begin{tabular}{|c|c|}
\hline Method of Surgery & Average No. of visit per Patients \\
\hline ECCE & 5 \\
\hline ECCE with PCIOL & 5 \\
\hline Small incision & 3 \\
\hline Phaco-emulsification & 2 \\
\hline
\end{tabular}




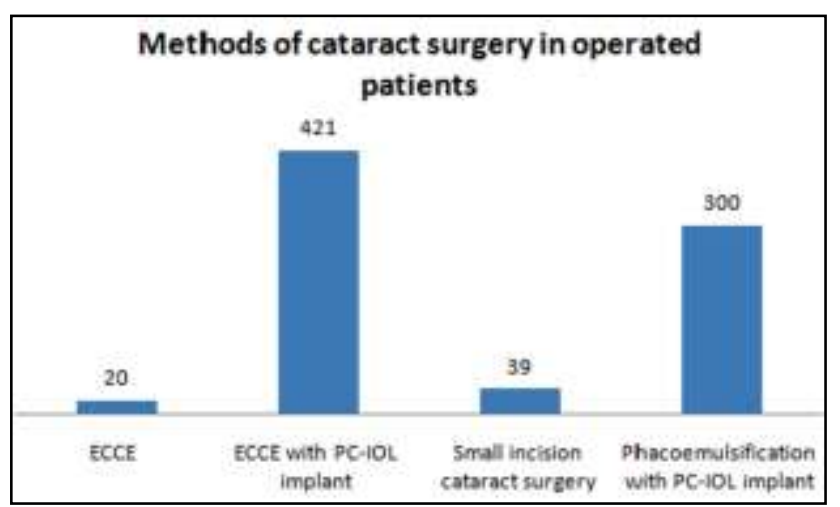

Fig. 1: Methods of cataract surgery in operated patients

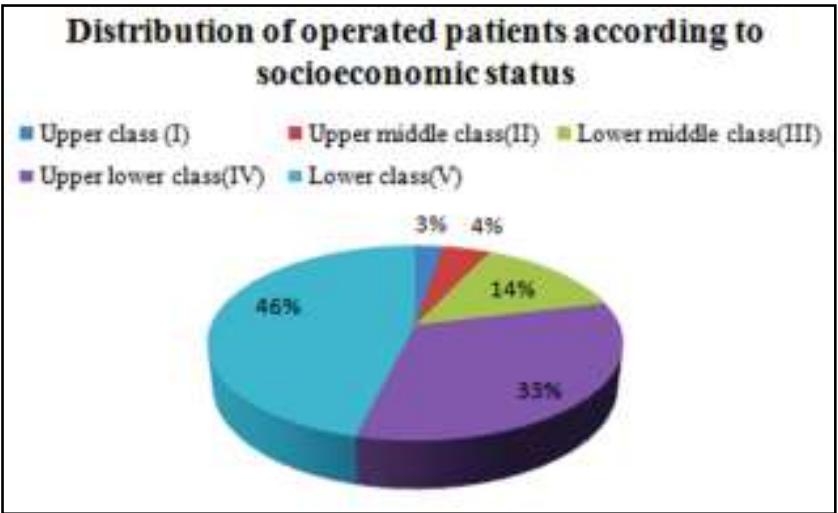

Fig. 2: Distribution of operated patients according to socioeconomic status

\section{Discussion}

Blindness continues to be one of the major public health problems in developing countries. Cataract and corneal diseases are major causes of blindness in countries with less-developed economies. ${ }^{7}$ Cataract is the most common easily correctable cause of blindness in the developing regions of the world. In India alone, 3.8 million people become blind from cataract each year. ${ }^{8}$ In spite of the progress made in surgical techniques in many countries during the last ten years, cataract $(47.9 \%)$ remains the leading cause of visual impairment in all areas of the world, except for developed countries. ${ }^{9}$

The ultimate solution for such cataract blind is performing cataract surgeries on a large scale. This may be carried out by cataract camps, comprehensive eye care camps and base hospital approach with screening camps. Base hospital approach is an important alternative to peripheral eye camps, which includes screening of patients in screening camps, their transfer to the base hospital and surgery in the base hospital. Efforts to tackle cataract blindness in India have been going on in earnest for the last three decades. More recently, the WHO global initiatives have called for a dramatic increase in surgical volumes world-wide. ${ }^{10}$ However, the outcomes of cataract surgery must be further examined. ${ }^{11}$

In 1994, Natchiar et al suggested that productivity per individual surgeon/unit should be increased through a high volume, high quality cataract surgery approach to solve the problem of India's curable blind. ${ }^{12}$ Some recent studies of high volume cataract surgery in India and Nepal report descent results. ${ }^{13-16}$ High quality, high volume cataract surgery is needed in community eye care centres to effectively manage the large backlog of cataract blindness. ${ }^{12}$

Female patients [2516(52.82\%)] outnumbered male patients [2247 (47.18\%)] during outpatient clinic. Female patients were more because of illiteracy, lack of medical awareness, accompanying person and financial problems.The main diseases seen during our outpatient clinic were cataract $(53.58 \%)$, refractive error $(16.76 \%)$, corneal opacity $(8.34 \%)$, glaucoma $(3.89 \%)$, conjunctivitis $(3.2 \%)$ and aphakia (3.76\%). According to NPCB survey (1999), the main causes of blindness in India were cataract (53-57\%), refractive error (18-20\%), corneal blindness (3$15 \%)$, glaucoma (4\%). It is estimated that $1.1 \%$ general population is blind. The problem of blindness is much more in rural areas as compared to urban areas, because of lack of specialized facilities and qualified ophthalmologists.

There was a difference between the three groups (ECCE, SICS and Phaco) for the best corrected postoperative visual acuity; $93.5 \%$ patients of the ECCE group, 99\% of the MSICS group and 98.5\% in Phaco group have postoperative vision of $6 / 18$ or better. These results are comparable with the results seen in Madurai Intraocular Lens Study (MILS) ${ }^{17}$ and the phaco trial in England ${ }^{18}$. But these results does not match with the outcomes in Tilganga Eye Hospital, Kathmandu, Nepal; $87.1 \%$ patients had corrected postoperative visual acuity better than 6/18 after 2 months in a community eye hospital based setting. ${ }^{19}$

There was a poor outcome (postoperative visual acuity $<6 / 60$ ) in $3.3 \%$ patients of ECCE group and $1 \%$ of Phaco group. This is similar to complications and poor outcomes in MILS $^{17}$ and the phaco trial. ${ }^{18}$ Great care was taken to maintain asepsis during the preoperative, surgical and postoperative procedures. The patients and health workers were educated to recognise, analyse and report any sign of infection. ${ }^{20}$ The posterior capsular rent was the commonest major intraoperative complication and corneal edema, iritis, posterior capsular opacification were the commonest postoperative complications. The complication rates were comparable to previous studies. ${ }^{20}$

In this study, we compared visual outcomes and complications of ECCE,SICS and Phacoemulsification simultaneously for the first time in camp patients. Also, we distributed patients undergoing cataract surgery according to socio-economic status using Nalwa criteria first time, according to which $82 \%$ of patients were from lower socioeconomic class.

\section{Limitations of the study}

The preoperative astigmatism and postoperative astigmatic decay were not compared. Also endothelial cell count, before and after both the techniques was not recorded due to lack of necessary equipment. The surgeons had experience of high quality high volume surgery, which may not be 
available at every place. The surgeon learning curves were not explored, as also the different styles.

\section{Conclusions}

In a developing country with limited resources and a vast population, maximum utilization of available facilities and prioritization of healthcare commitments need to be proportioned rationally. The success of modern cataract surgery is the result of a long and exciting process. Currently, the biggest challenge is to reduce cataract blindness in the developing world, where cataract accounts for more than half of all blindness. The concept of base camp approach for mass cataract surgery has gaining popularity in recent times. The study shows that adopting newer surgical approaches at base camps gives easily visual rehabilitation, better visual outcomes and compliance, and lesser complications compared to older methods.

Phaco-emulsification and small incision cataract surgery are safer than conventional ECCE surgery. Both procedures gives best corrected postoperative visual acuity of $6 / 18$ or better in most of patients. A large proportion of patients do not wear their postoperative refractive correction. ${ }^{21}$ Considering this, wherever the requisite surgical expertise is available, Phaco-emulsification and small incision cataract surgery are recommended as the procedure of choice for effective rehabilitation of the cataract patients.

\section{Source of Funding}

None.

\section{Conflict of Interest}

None.

\section{References}

1. Song, E. Age-related cataract, cataract surgery and subsequent mortality: a systematic review and meta-analysis. PLoS One 2014;9:e112054.

2. Salomon, J. A. et al. Healthy life expectancy for 187 countries, 1990-2010: a systematic analysis for the Global Burden Disease Study 2010. Lancet 2012;380:2144-62.

3. Pathengay, A., Flynn, H. W., Isom, R. F. \& Miller, D. Endophthalmitis outbreaks following cataract surgery: causative organisms, etiologies, and visual acuity outcomes. $J$ Cataract Refract Surg 2012;38:1278-82.

4. Stevens, G. A. et al. Global prevalence of vision impairment and blindness: magnitude and temporal trends, 1990-2010. Ophthalmol 2013;120;2377-84.

5. Ono K., Hiratsuka, Y. \& Murakami, A. Global inequality in eye health: country-level analysis from the Global Burden of Disease Study. Am J Public Health 2010;100:1784-88.
6. Johns, A. W. The role of international non-governmental organisations in dealing with cataract blindness in developing countries. Doc Ophthalmo 1992;81:345-8.

7. Garg P, Krishna PV, Stratis AK, Gopinathan U. The value of corneal transplantation in reducing blindness. Eye (Lond) 2005;19:1106-14.

8. Minassian DC, Mehra V. 3.8 million blinded by cataract each year: projections from the first epidemiological study of incidence of cataract blindness in India. Br J Ophthalmol 1990;74:341-3.

9. Causes of blindness and visual impairment. Available from: http://www.who.int/blindness/causes/en/

10. Thylefors B. A global initiative for the elimination of avoidable blindness. Am J Ophthalmol 1998;125:90-3.

11. Foster A. Cataract - A global perspective: Output, outcome and outlay. Eye (Lond) 1999;13 (Pt 3b):449-53.

12. Natchiar G, Robin AL, Ravilla D. Attacking the backlog of India's curable blind. Arch Ophthalmol 1994;112:987-93.

13. Natchiar G, DabralKar T. Manual small incision suture less cataract surgery - an alternative technique to instrumental phacoemulsification. Operative Tech Cataract Refract Surg 2000;3:161-70.

14. Balent LC, Narendran K, Patel S. High volume sutureless intraocular lens surgery in a rural eye camp in India. Ophthalmic Surg Lasers 2001;32:446-55.

15. Prajna NV, Chandrakanth Ks, Kim R. The Madurai intraocular lens study II: Clinical outcomes. Am J Ophthalmol 1998;125:14-25.

16. Hennig A, Kumar J, Yorston D. Sutureless cataract surgery with nucleus extraction: outcome of a prospective study in Nepal. Br J Ophthalmol 2003;87:266-70.

17. Prajna V, Chandrakanth KS, Kim R. The Madurai intraocular lens study II: Clinical outcomes. Am J Ophthalmol 1998; 125:14-25.

18. Minassian DC, Rosen P, Dart JKG, et al. Extracapsular cataract extraction compared with small incision surgery by phacoemulcification: a randomised trial. $\mathrm{Br}$ J Ophthalmol 2001;85:822-9.

19. Ruit S, Tabin GC, Nissman SA, et al. Low cost high volume extracapsular cataract extraction with posterior chamber intraocular lens implantation in Nepal. Ophthalmol 1999;106:1887-92.

20. Gogate PM, Deshpande M, Wormald RP, et al. Extracapsular cataract surgery compared with manual small incision cataract surgery in community eye care setting in western India: a randomised controlled trial. Br J Ophthalmol 2003;87:667-72.

21. Hogweg M, Sapkota YK, Foster A. Acceptability of apakic correction: results from Karnali eye camp in Nepal. Acta Ophthalmol 1992;70:407-12.

How to cite this article: Kumar S, Singh BK, Bhalerao SA. Evolution of cataract surgery in relation to visual outcome and ease of surgery in eye camps in Meerut and vicinity (Northern India). Int $J$ Ocul Oncol Oculoplasty 2019;5(3):118-23. 